УДК 573.6

\title{
Rheology of Polyhydroxyalkanoate Solutions
}

\author{
Dmitry B. Goncharov and Alexey G. Sukovatyi* \\ Institute of Biophysics $S B R A S$ \\ 50/50 Akademgorodok, Krasnoyarsk, 660036, Russia
}

Received 03.06.2015, received in revised form 30.01.2016, accepted 25.04.2016

The rheology of solutions of polyhydroxyalkanoates in chloroform and dichloromethane was studied. The dynamic viscosity of solutions depended on type of solvent and PHA. The polymer solutions with increase of temperature behave as Newtonian fluids. Dynamic viscosity was increasing with the concentration of polymer in solution, regardless of the solvent. Solutions of PHAs in descending order of magnitude of dynamic viscosity can be positioned in the following order: $P(3 H B)-P(3 H B-3 H V)-$ $P(3 G B-3 H H)-P(3 H B-4 H B)$. The magnitude of the dynamic viscosity of solutions based on chloroform in 3-3,5 times higher than that of solutions based on dichloromethane at identical concentration and temperature. The obtained values of dynamic viscosity have demonstrated the dependence of rheological parameter on the chemical composition of the polymer, and the characteristics of solvent (composition, temperature, and concentration).

Keywords: polyhydroxyalkanoates, dynamic viscosity, chloroform, dichloromethane.

DOI: 10.17516/1997-1389-2016-9-2-190-197.

(C) Siberian Federal University. All rights reserved

* Corresponding author E-mail address: a.sukovatiy@ya.ru 


\title{
Реология растворов полигидроксиалканоатов
}

\author{
Д.Б. Гончаров, А.Г. Суковатый \\ Институт биофизики СО РАН \\ Россия, 660036, Красноярск, Академгородок, 50/50
}

Исследована реология растворов ПГА различного химического строения в хлороформе и дихлорметане. Показано, что динамическая вязкость растворов зависит от типа растворителя и типа ПГА, при этом исследуемые растворы полимеров при увеличении температуры ведут себя как ньютоновские жидкости. Повышение концентрации полимеров в растворе способствует увеличению динамической вязкости независимо от растворителя. Растворы ПГА по убыванию величины динамической вязкости можно расположить в следующем порядке: П(ЗГБ) - П(ЗГБ-ЗГВ) - П(ЗГБ-ЗГГ) - П(ЗГБ-4ГБ). При этом величина динамической вязкости растворов при одинаковых концентрации и температуре у растворов на основе хлороформа в 3-3,5 раза выше, чем у растворов на основе дихлорметана. Полученные значения динамической вязкости для разных типов полигидроксиалканоатов и двух основных типов растворителей свидетельствуют о зависимости исследуемого реологического параметра как от химического состава полимера, так и от характеристик (состав, температура, концентрация) используемого растворителя.

Ключевые слова: полигидроксиалканоаты, динамическая вязкость, хлороформ, дихлорметан.

\section{Введение}

Полигидроксиалканоаты (ПГА) - биодеградируемые и биосовместимые линейные полиэфиры микробиологического происхождения - являются перспективным материалом для изготовления изделий, пригодных для применения в различных сферах. Важным технологическим свойством ПГА является возможность переработки общепринятыми методами: испарением растворителя, техникой микроинкапсулирования, холодного прессования порошков, прессованием и экструзией расплавов - из различных фазовых состояний (растворов, эмульсий, порошков, расплавов) (Волова и др., 2006). Разнообразные изделия из ПГА (пленки, мембраны, микрогранулы и микрочастицы), предназначенные для депонирования и доставки биологически активных соединений и лекарствен- ных средств, а также препаратов для защиты культурных растений от сорняков, вредителей и возбудителей болезней культурных растений, могут быть получены из растворов этих полимеров.

Для получения специализированных полимерных изделий из растворов необходимы знания основных реологических свойств таких полимерных систем. Наиболее значимым параметром растворов служит динамическая вязкость, которая характеризует не только реологию растворов и смешивание компонентов в растворах, но также определяет характеристики переноса массы и тепла в структуре системы полимер - растворитель (Collier et al., 1998; Weissberg et al., 1951). Вязкость является важным фактором, который определяет физические характеристики процесса разделения фаз в растворах полимеров 
разных типов, а это, в свою очередь, определяет выбор реагентов для растворения полимеров различного химического строения (Li et al., 2014; Lai et al., 2008; El-Hefian et al., 2008, 2009; Diasa et al., 2013; Tjader, 2005). Сведения о вязкости полимерных растворов в целом необходимы для формирования фундаментальных представлений о взаимодействии полимеров с различными растворителями. Относительно ПГА информация о реологии растворов полимеров этого семейства весьма ограничена.

Целью данного исследования было изучение динамической вязкости растворов полигидроксиалканоатов различного химического строения, полученных с использованием различных растворителей.

\section{Материалы и методы}

В работе использовали образцы ПГА различного химического строения и свойств, синтезированные в лаборатории хемоавтотрофного биосинтеза Института биофизики CO PAH (Volova et al., 2008; 2011).

Были взяты: гополимер 3-гидркосибутирата [П(ЗГБ)], сополимеры П(ЗГБ) с 3-гидроксивлаератом (3ГВ); 3-гидроксигексаноатом (3ГГ), 4-гидркосибутиратом (4ГБ). Химический состав и свойства используемых образцов полигидроксиалканоатов представлены в табл.
Химическую структуру образцов ПГА определяли после предварительного метанолиза проб по метиловым эфирам ЖК на хромато-масс-спектрометре GCD plus (Hewlett Packard, США); степени кристалличности - на рентгеноспектрометре D8 ADVANCE «Bruker» (Германия) (графитовый монохроматор на отраженном пучке). Молекулярную массу и молекулярно-массовое распределение ПГА исследовали с использованием хроматографа для гель-проникающей хроматографии Breeze System (Waters, США) относительно полистироловых стандартов (Fluka, Швейцария, Германия).

В качестве растворителей использовали хлороформ и дихлорметан («Химреактивснаб», Россия). Динамическую вязкость готовых полимерных растворов определяли с помощью вискозиметра Гепплера (ГОСТ 8420-74) фирмы Haake Thermo Scientific (Германия). Методика измерения заключалась в следующем: стеклянную трубку вискозиметра устанавливали вертикально и заполняли испытуемым раствором на 1-2 см выше верхней метки. В случае образования пузырьков воздуха их удаляли стеклянной палочкой после поднятия на поверхность. Затем свободно опускали стальной шарик в центр трубки и в момент достижения нижним краем шарика верхней метки включали секундомер. Когда шарик достигал нижним краем нижней метки

Таблица. Химический состав и свойства полигидроксиалканоатов

\begin{tabular}{|c|c|c|c|c|c|c|}
\hline Номер & ПГА & $\mathrm{M}_{\mathrm{B}}(\mathrm{kDa})$ & $Đ$ & $\mathrm{~T}_{\text {мелт }}\left({ }^{\circ} \mathrm{C}\right)$ & $\mathrm{T}_{\text {дегр }}\left({ }^{\circ} \mathrm{C}\right)$ & $\mathrm{C}_{\mathrm{x}}(\%)$ \\
\hline 1 & П(3ГБ) & 922 & 251 & $179 \pm 16$ & $2948 \pm 26$ & 75 \\
\hline 2 & П(ЗГБ-со-9,9 мол. \%-3ГВ) & 695 & 315 & $1731 \pm 15$ & $2835 \pm 25$ & 59 \\
\hline 3 & П(ЗГБ-со-9 мол. \%-3ГГ) & 647 & 330 & $1738 \pm 15$ & $2461 \pm 22$ & 62 \\
\hline 4 & П(3ГБ-со-13,4 мол. \%-4ГБ) & 924 & 410 & $1747 \pm 15$ & $2838 \pm 25$ & 35 \\
\hline
\end{tabular}

Примечание: $\mathrm{M}_{\mathrm{s}}$ - средневесовая молекулярная масса, Đ - полидисперсность, $\mathrm{T}_{\text {мелт }}$ - температура плавления, $\mathrm{T}_{\text {дегр }}$ - температура термической деградации, $\mathrm{C}_{\mathrm{x}}-$ степень кристалличности 
трубки, секундомер останавливали и отсчитывали время прохождения шарика в секундах между двумя метками трубки вискозиметра с погрешностью не более 0,2 с.

Расчёт динамической вязкости производили по формуле

$$
\eta=k \cdot \tau \frac{\rho_{u}-\rho_{p}}{100},
$$

где $\mathrm{k}$ - коэффициент шарика, вычисленный по калибровке шарика жидкостью с известной вязкостью, $\tau$ - время падения шарика между

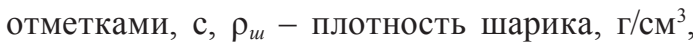

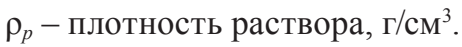

\section{Результаты и обсуждение}

Из образцов полигидроксиалканоатов различного химического состава были изготовлены полимерные растворы с концентрациями (С, \%) от 1 до 10 вес. \% с использованием хлороформа и дихлорметана. Динамическая вязкость была измерена при изменении температуры от 5 до $60{ }^{\circ} \mathrm{C}$ для хлороформа и от 5 до $40{ }^{\circ} \mathrm{C}$ для дихлорметана с шагом изменения температуры $5^{\circ}$. Полученные результаты представлены на рис.

\section{Влияние химического состава ПГА}

на динамическую вязкость растворов

Сравнение абсолютных значений динамической вязкости растворов ПГА различного химического состава в растворителе одного типа было проведено при температуре $25{ }^{\circ} \mathrm{C}$ и концентрации полимера в растворе $5 \%$. Для растворов различных типов ПГА в хлороформе получены значения динамической вязкости, существенно различающиеся между собой. Для растворов П(ЗГБ) зафиксированы самые высокие показатели вязкости (1161,84 сП). Для сополимеров П(ЗГБ-со-13,4 мол. \%-4ГБ) - 19,11 сП, что отличается от аналогичного значения для П(ЗГБ) более чем в 60 pa3. Раствор П(ЗГБ-со-9,9 мол. \%-ЗГВ) показал значение вязкости 258,12 сП, что в 4,5 раза меньше по сравнению с гомополимером. Для сополимера П(ЗГБ-со-9 мол. \%-ЗГГ) значение вязкости составило 53,89 сП, это меньше чем у П(ЗГБ) в 21,5 раза.

При использовании в качестве растворителя дихлорметана показатели динамической вязкости по абсолютным значениям при прочих равных условиях значительно отличались от показателей, зарегистрированных для растворов этих же типов ПГА в хлороформе.

Самое высокое значение динамической вязкости зарегистрировано на уровне 311,06 сП для раствора П(ЗГБ), что практически в 3 раза ниже, чем у раствора этого типа ПГА в хлороформе. Для образца П(ЗГБ-со-9,9 мол. \%-3ГВ) динамическая вязкость составила 69,1 сП, что существенно ниже, чем у П(ЗГБ). Самые низкие значения динамической вязкости характерны для растворов П(3ГБ-со-13,4 мол. \%-4ГБ) - 5,11 сП и П(ЗГБсо-9 мол. \%-3ГГ) -14,42 сП в дихлорметане, что отличается от П(ЗГБ) в 60 и в 21 раз соответственно.

\section{Зависимость динамической вязкости растворов ПГА от температуры и концентрации раствора}

При изучении температурной зависимости динамической вязкости полимерных растворов наблюдали снижение этого параметра с увеличением температуры раствора для всех исследованных типов ПГА независимо от применяемого растворителя. При этом для всей исследованной температурной шкалы абсолютные значения вязкости у растворов на основе хлороформа были выше в 3-3,5 раза, чем у растворов ПГА в дихлорметане. Достигнутые результаты показывают возможность получения растворов ПГА с 


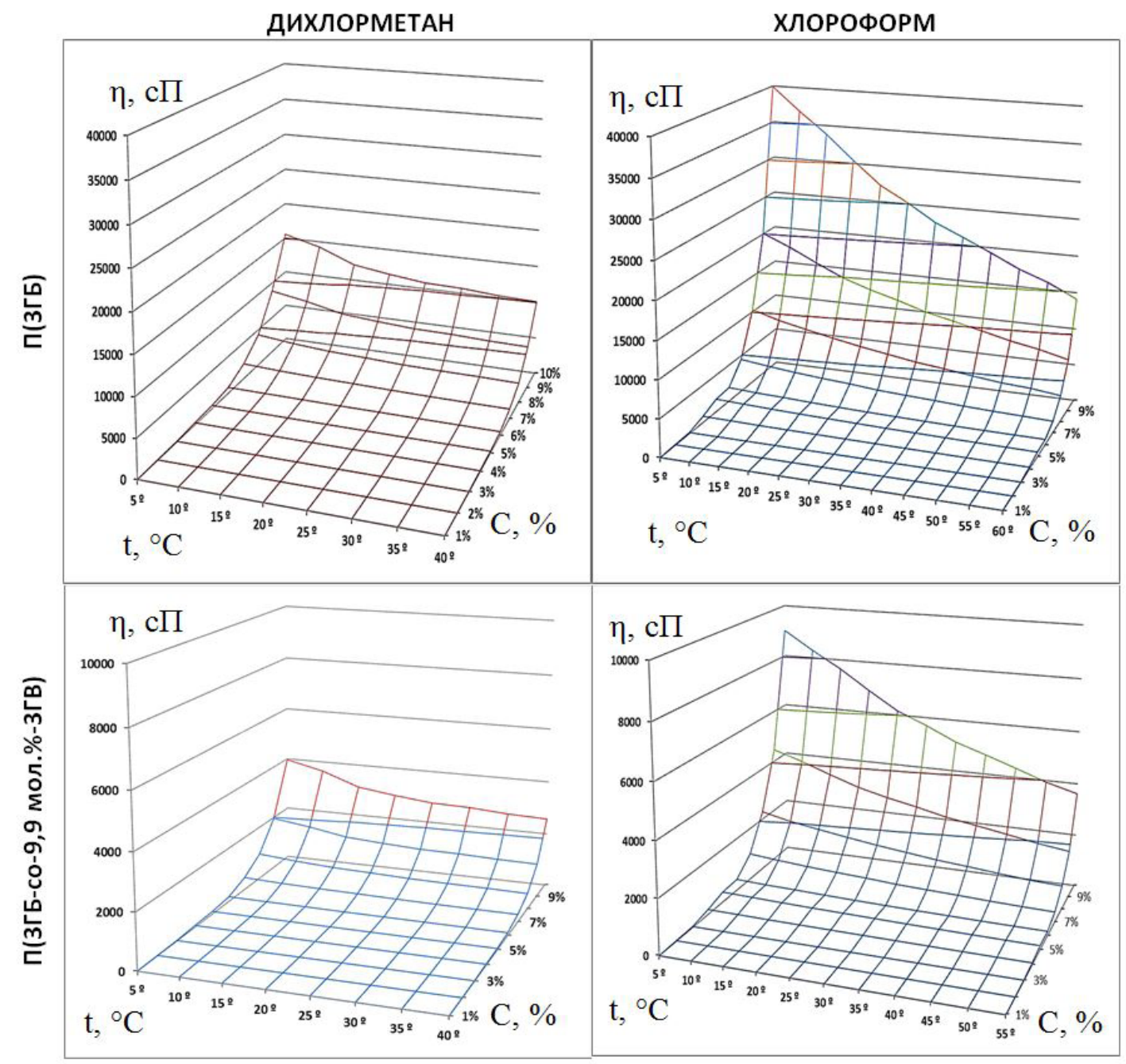

Рисунок. Зависимость динамической вязкости полимерного раствора полигидроксиалканоатов от температуры и концентрации раствора 

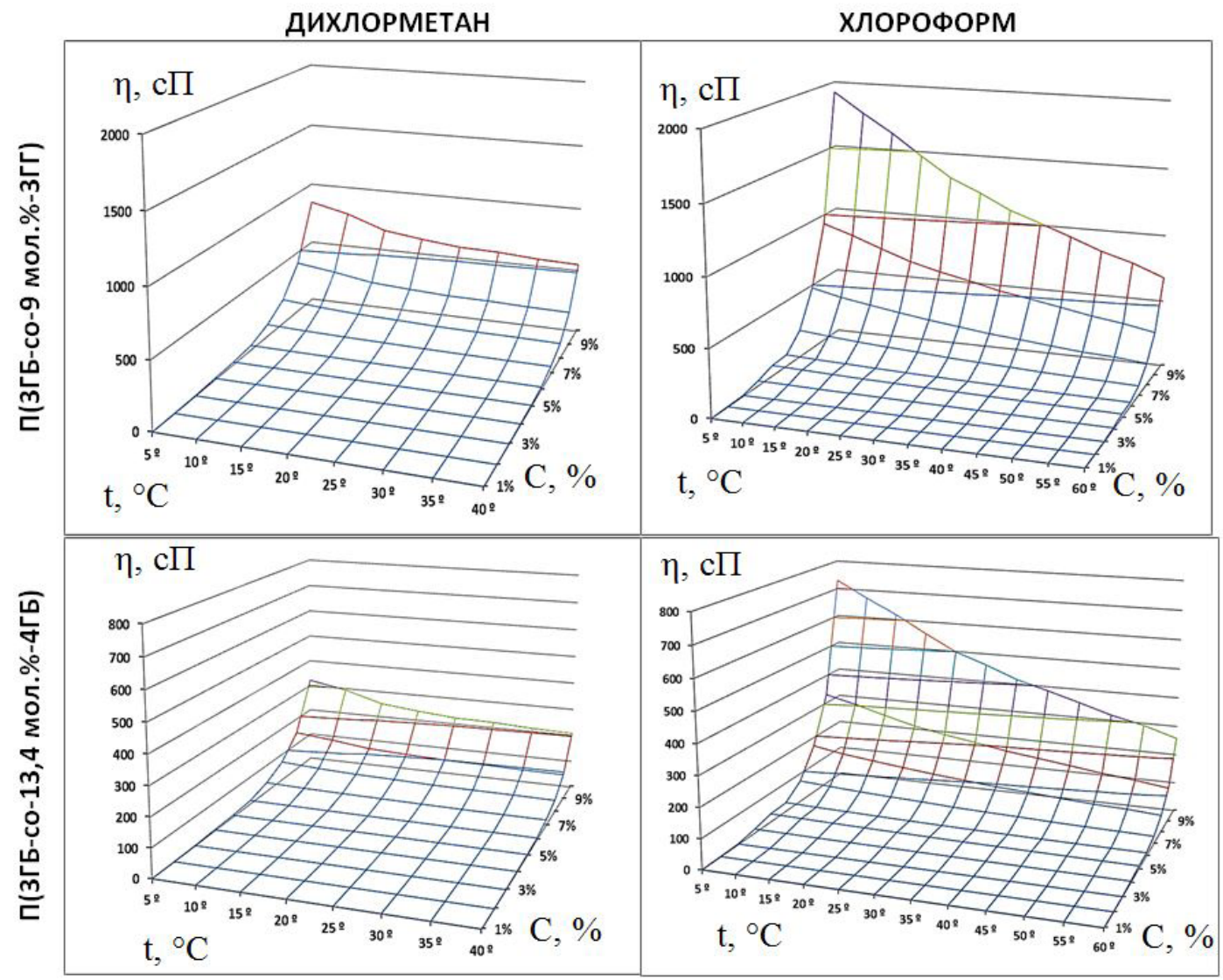

Продолжение рисунок. Зависимость динамической вязкости полимерного раствора полигидроксиалканоатов от температуры и концентрации раствора 
различной динамической вязкостью, изменяя тип растворителя.

Полученная зависимость динамической вязкости растворов ПГА от температуры свидетельствует о ньютоновском поведении полимерных растворов разного химического строения для исследованных растворителей. Этот характер изменения динамической вязкости раствора объясняется увеличением теплового движения молекул полимера в растворе.

Зависимость динамической вязкости раствора от концентрации полимера продемонстрировала нелинейный характер для обоих типов растворителей. При этом для одних и тех же значений температуры полимерного раствора при использовании хлороформа в качестве растворителя скорость изменения динамической вязкости значительно превышала аналогичный параметр для дихлорметана.

Так, при увеличении концентрации полимерного раствора от 1 до $10 \%$ при температуре $25{ }^{\circ} \mathrm{C}$ наибольший рост показателей динамической вязкости зафиксирован для сополимера П(ЗГБ-со-9,9 мол. \%-3ГВ), от 1,92 сП до 6159,52 сП при использовании хлороформа и от 1,61 сП до 2765,14 сП при использовании дихлорметана.

В меньшей степени изменения параметра характерны для сополимера П(ЗГБсо-13,4 мол. \%-4ГБ). От 0,67 сП до 498,69 сП при использовании хлороформа и от 0,57 сП до 223,87 сП у растворов на основе дихлорметана.
Для гомополимера П(ЗГБ) зафиксированы изменения от 8,66 сП до 27274,61 сП и от 7,27 сП до 10836,10 сП для хлороформа и дихлорметана соответственно. Сополимер П(ЗГБ-со-9 мол. \%-ЗГГ) показал изменения вязкости от 1,06 сП до 1314,00 сП для хлороформа и от 0,89 сП до 589,88 сП для дихлорметана.

Полученные данные свидетельствуют о том, что при использовании хлороформа в качестве растворителя концентрация раствора оказывает существенно большее влияние на систему «полимер - растворитель» как параметра, определяющего динамическую вязкость, чем при использовании дихлорметана.

\section{Заключение}

Исследована реология растворов ПГА различного химического строения в хлороформе и дихлорметане и установлены зависимости динамической вязкости от химического состава ПГА, плотности полимерных растворов и температуры среды. Растворы ПГА по убыванию величины динамической вязкости можно расположить в следующем порядке: П(ЗГБ) - П(ЗГБ-ЗГВ $)$ - П(ЗГБ-ЗГГ) - П(ЗГБ4ГБ). Динамическая вязкость растворов ПГА в хлороформе в 3-3,5 раза выше, чем у растворов на основе дихлорметана. Полученные результаты позволяют получать растворы ПГА с различными реологическими характеристиками, что важно для получения полимерных изделий растворными технологиями.

\section{Работа выполнена за счет средств Российского научного фонда (грант № 14-26- 00039).}

\section{Список литературы}

Волова Т.Г., Севастьянов В.И., Шишацкая Е.И. (2006) Полиоксиалканоаты - биоразрушаемые полимеры для медицины. Шумаков В.И. (ред.) Красноярск, Платина, 288 с. [Volova T.G., Sevastyanov V.I., Shishatskaya E.I. (2006) Polyhydroxyalkanoates - biodestructible polymers for medicine. Shumakov V.I. (ed.) Krasnoyarsk, Platina, 288 p. (in Russian)] 
Collier J.R., Romanoschi O., Petrovan S. (1998) Elongational rheology of polymer melts and solutions. Journal of Applied Polymer Science, 69: 2357-2367

Diasa J.R., Antunesb F.E., Bártoloa P.J. (2013) Influence of the rheological behaviour in electrospun PCL nanofibres production for tissue engineering applications. Chemical Engineering Transactions, 32: $1015-1020$

El-Hefian E.A., Khan R.A., Yahaya A.H. (2008) Study of the parameters affecting the viscosity of chitosan solutions. Journal Chemical Society of Pakistan, 30(4): 529-531

El-Hefian E.A., Yahaya A.H., Misran M. (2009) Characterisation of chitosan solubilised in aqueous formic and acetic acids. Maejo International Journal of Science and Technology, 3(03): 415-425

Lai G., Li Y., Li G. (2008) Effect of concentration and temperature on the rheological behavior of collagen solution. International Journal of Biological Macromolecules, 42(3): 285-291

Li Y., Qiao C., Shi L., Jiang Q., Li T. (2014) Viscosity of collagen solutions: influence of concentration, temperature, adsorption, and role of intermolecular interactions. Journal of Macromolecular Science, Part B: Physics, 53(5): 893-901

Tjader K.E. (2005) Rheology of Polyhydroxyalkanoates: A Study of a Class of “Green" Polymers. University of Tennessee Honors Thesis Projects. http://trace.tennessee.edu/utk_chanhonoproj/922

Volova T.G, Zhila N.O., Kalacheva G.S., Sokolenko V.A., Sinskey A.J. (2011) Synthesis of 3-hydroxybutyrate-co-4-hydroxybutyrate copolymers by hydrogen-oxidizing bacteria. Applied Biochemistry and Microbiology, 47: 494-499

Volova T.G., Kalacheva G.S., Steinbüchel A. (2008) Biosynthesis of multi-component polyhydroxyalkanoates by the bacterium Wautersia eutropha. Macromolecular Symposia, 269: 1-7

Weissberg S.G., Simha R., Rothman S. (1951) Viscosity of dilute and moderately concentrated polymer solutions. Journal of Research of the National Bureau of Standards, 47(3): 2257-2274 